\title{
Where are all the women in tech?
}

Written by: Ileana Epsztajn, OECD Observer editor-at-large

Last update: 2 March 2020

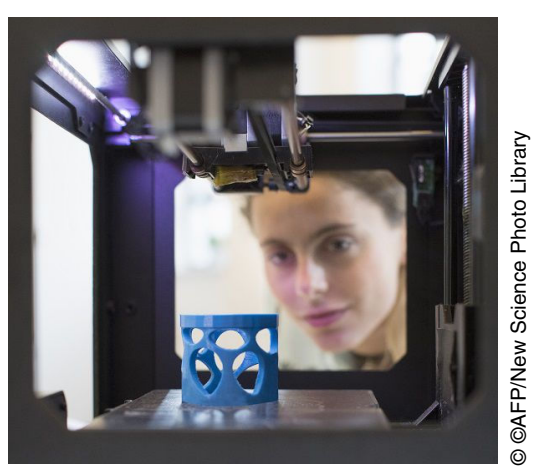

Where are all the women in tech? I Image for Where are all the women in tech article

For proof that the tech industry is not particularly welcoming to women, one need look no further than Google, where women account for just $31 \%$ of headcount, falling to a mere $20 \%$ in pure tech roles. They are also paid less than their male counterparts, according to a class action lawsuit filed in 2017 by three former employees on behalf of "all women employed by Google in California" for discrimination and unequal pay for equal work. Which did nothing to stop another former employee, who had been laid off after circulating a sexist memo, lodging his own complaint against the Internet giant for "ostracising" conservative white men.

So can the fourth industrial revolution catalyse increased equality between the sexes, or should we be fearing instead that it will even further marginalise women in the workplace? One of the sessions of the 2018 OECD Forum took a closer look at "Women in Tech".

As highlighted by a recently published OECD report-The Pursuit of Gender Equality. An Uphill Battle-by the time they reach higher education, women are underrepresented in STEM subject areas (science, technology, engineering and mathematics), in which they currently account for just $19 \%$ of students in OECD 
countries. Those who do go into tech jobs are twice as likely as men to leave them. This is why chairman Stefan de Vries, on opening the Forum session, commented wryly that a better title would have been "the lack of women in tech".

How did we get here? The observations made by the mostly female panel could very easily have been made of other sectors. Susana Balbo, for example, the first female winemaker in Argentina, and Chair of the W20, an international network taking women's voices to the G20, reminded the participants that for women working in male-dominated fields, the major difficulty is having to work twice as hard as the men and paying a very high price out of one's personal life to reach the same professional level. Emmanuelle Quilès, CEO of Janssen France, added that female role models were rare and prejudices persistent. To appreciative laughter from the audience, she described how people's conversation dries up when she tells them that her daughter is studying mechanical engineering.

The big problem with these prejudices is that they are a primary cause of one of the main obstacles preventing women from fully embracing the STEM sector, and others: a lack of confidence.

All members of the panel agreed on the importance of this problem. Tarah Wheeler, entrepreneur and author of Women in Tech, spoke at some length about women's reluctance to promote themselves and to believe in their abilities without the external validation of a man. Stefan de Vries took up the same theme, recounting the experience he had when looking to interview women who were acknowledged experts in their field: their first response was invariably "I'm not sure I'm the right person"-something he had never heard from any of their male counterparts.

Emmanuelle Quilès described how it had been shown that people who were used to living in a competitive environment and to exaggerating their self-confidence and their abilities were also those most likely to successfully obtain a promotion or pass an exam, and she concluded that there was an urgent need to push women to achieve this self-belief too.

But how?

For Chiara Condi, President and founder of Led by Her, there are two answers to this question. First, women need to be more self-reliant, and this is what her association does, by helping them rebuild their lives through entrepreneurship. Too many women have been robbed of their rights and their route to selfrealisation by their personal history or their environment; they need to be given the means to unlock their own lives in order to be able to become what they want to be, and entrepreneurship helps them to do this. IT can be a powerful force in this context: Aleph Molinari, President of the Fundación Proaccesso, which helps the underprivileged, in many cases women, to acquire computer skills, talked about research by the University of Pennsylvania which found that women who had completed a basic computing course had four times more chances of 
finding work. He pressed the point that encouraging girls to take coding courses, for example, would subsequently help them to do well in STEM careers.

The second answer is that our culture also needs to change if we are to really make room for women in the professional world. This will take a conscious effort by businesses, which can set up special training courses, for example, ensure that sexist behaviour is banned from the workplace and that the corporate culture is sufficiently diversified for women to feel comfortable-and, naturally, pay them as much as the men. Of course, for this change to really happen in the business world, it has to be embraced by men, who are largely in charge of it. More generally, all of society has to change the way it views women in the workplace. Education needs to encourage women to consider STEM careers and to aim for higher levels of responsibility. Both Béatrice Clicq, Confederal Secretary of the French trade union Force ouvrière, and Susana Balbo argued that women ought not to be the only parents juggling their responsibilities in the home and in the workplace, and mandatory paternity leave could be part of the solution to that problem. In her closing remarks, Monika Queisser, Head of Social Policy in the OECD's Directorate for Employment, Labour and Social Affairs, made the very pertinent observation that we will never achieve equal pay for equal work if we don't solve the problem of equality in unpaid work.

Against the backdrop of the fourth industrial revolution, this session highlighted the extent to which the digital transformation has intensified most social issues. Béatrice Clicq cited an American report which found that $47 \%$ of jobs would disappear in the digital revolution, and most of these jobs (65\%) were currently held by women. The new jobs that would be created would be focused on the STEM sector, and STEM subjects are heavily dominated by male students. There therefore remains much work to be done to ensure that gender inequality does not worsen in the future, and that women, who represent $51 \%$ of the population and $60 \%$ of graduates, can finally claim equality in the workplace.

๑) OECD Observer No 315 Q3 2018

\section{References}

See the session of the 2018 OECD Forum, Women in Tech: https:// oecd.streamakaci.com/052018/vod/day/1/room/3/hour/10:45/lang/fl https:// oecd.streamakaci.com/052018/vod/day/1/room/3/hour/10:45/lang/fl

OECD (2018), The Pursuit of Gender Equality. An Uphill Battle, OECD Publishing, Paris, http://dx.doi.org/10.1787/9789264203426-fr http://dx.doi.org/http:// dx.doi.org/10.1787/9789264203426-fr

http://www.oecd.org/gender/ http://www.oecd.org/gender/ 